\title{
O IMPACTO DA COVID19 NO COTIDIANO ESCOLAR: UM ESTUDO SOBRE O TRABALHO DE GESTORES ESCOLARES EM JACOBINA/BA
}

http://dx.doi.org/10.5902/2318133863188

\author{
Ione Oliveira Jatobá Leal ${ }^{1}$ \\ Cristiane Regina Dourado Vasconcelos ${ }^{2}$ \\ Lenizan Passos Rios ${ }^{3}$ \\ Jomária Alessandra Queiroz de Cerqueira Araújo ${ }^{4}$
}

\begin{abstract}
Resumo
Este artigo decorre de uma pesquisa exploratória cujo objetivo foi compreender as mudanças ocorridas no trabalho de gestores escolares com a pandemia da Covid-19. O trabalho da gestão envolve uma série de atribuições inerentes às dimensões que orientam o funcionamento das escolas e a chegada da pandemia fez com que, de forma emergencial, estes profissionais tivessem suas formas de atuação alteradas. A pesquisa foi desenvolvida com gestores de escolas municipais de Jacobina/BA. A análise de dados permite-nos inferir que os gestores envidaram esforços para garantir a oferta do ensino e funcionamento das escolas e têm enfrentaram dificuldades para executar suas atividades de forma remota.

Palavras-chave: gestão escolar; trabalho dos gestores; escolas municipais; pandemia.

\section{THE IMPACT OF COVID-19 ON SCHOOL LIFE: A STUDY ABOUT THE WORK OF SCHOOL MANAGERS IN JACOBINA/BA}

\begin{abstract}
This article is the result of an exploratory research whose objective was to understand the changes that occurred in the work of school managers during covid-19 pandemic. Management's work involves a series of attributions inherent to the dimensions that guide the functioning of schools, and the sudden arrival of the pandemic caused these professionals have their forms of action changed in an emergency. The research was developed with principals of municipal schools in Jacobina/BA. Data analysis allows us to infer that managers are making efforts to guarantee the provision of teaching and school functioning and have been facing difficulties in carrying out their activities remotely.

Key-words: school management; work of managers; municipal schools; pandemic.
\end{abstract}

\footnotetext{
1 Universidade do Estado da Bahia, Brasil. E-mail: ionejatoba@gmail.com.

2 Universidade Federal do Rio Grande do Sul. E-mail: dourado.cris@gmail.com.

3 Universidade do Estado da Bahia, Brasil. E-mail: lenipassos85@gmail.com.

4 Universidade do Estado da Bahia, Brasil. E-mail: aqueiroz@gmail.com. 


\section{Introdução}

pandemia da Covid19 impôs mudanças nas rotinas pessoais e institucionais,
desde o isolamento social até a adoção de novos padrões de consumo, de
participação e convivência social, além de novas modalidades de trabalho. Neste sentido, aos profissionais da educação coube improvisar recursos e procedimentos que garantissem o ensino, especialmente nas redes públicas de ensino.

Ao longo dos oito meses de isolamento social discutiu-se sobre os desafios enfrentados pelos docentes, contudo, nota-se poucos estudos acerca do trabalho do gestor escolar diante deste contexto. Esta invisibilidade está ainda mais presente quando o lócus das pesquisas estão situados nas redes públicas municipais de ensino, em especial nas localizadas em municípios distantes das capitais. Assim, a rede pública municipal de ensino de Jacobina/BA foi escolhida como contexto para empreender uma pesquisa que projetasse uma amostra da ação dos gestores escolares nas redes públicas dos municípios baianos.

A escolha deste local tem relação com atividades desenvoldidas por integrantes do Grupo de Pesquisa em Gestão Educacional e Formação de Gestores, vinculado à Universidade do Estado da Bahia, com esta rede municipal, beneficiária de um curso de formação continuada destinado a gestores escolares. Assim, o contato promovido pelo curso, de formato híbrido, colaborou para uma rede de comunicação que proporcionou aporte para a pesquisa.

A partir desta relação constatou-se que após um mês da determinação do governo do Estado de suspender as atividades escolares, iniciaram-se os encontros virtuais e presenciais de atendimento da comunidade nas secretarias escolares. Este atendimento constitui-se da recepção da comunidade para solicitar e receber documentos, o desenvolvimento de atividades voltadas para impressão de materiais, a resposta às solicitações da Secretaria Municipal de Educação, quase sempre relativas a tabulação de informações e serviços de secretaria, como emissão de atestados, transferências, comprovantes de matrícula, entre outros.

A pesquisa teve como objetivo geral identificar os desafios enfrentados e as estratégias adotadas pelos gestores escolares da rede pública municipal de Jacobina/BA no processo de continuidade do ensino no ano letivo de 2020. Na execução e análise dos dados da pesquisa empírica integrantes do Nugef articularam parceria com membros do Grupo Diversidade, Formação, Educação Básica e Discursos, outro grupo de pesquisa ligado à Uneb. Essa articulação permitiu uma análise mais fidedigna dos dados, já que parte das investigações realizadas por este grupo tem seu lócus empírico situado nas redes de ensino de Jacobina/BA.

Diante dos dados os grupos de pesquisa identificaram que os gestores escolares presenciaram e vivenciaram um mudança abrupta na rotina escolar que impõe uma adaptação para garantir o funcionamento das escolas, mesmo de forma remota. Além disso os gestores têm o desafio de convencer e agregar a comunidade escolar, principalmente os professores, para desenvolverem atividades de forma remota, em alguns casos sem os recursos tecnológicos necessários para a efetivação das propostas pensadas pela comunidade escolar. 
Vale ressaltar que exercer as atividades administrativas e pedagógicas na escola, de forma presencial, apesar de ser um desafio para alguns diretores, ainda se torna mais fácil que gerir a escola e acompanhar o trabalho dos servidores remotamente. Este estudo apresenta dados que nos permite afirmar que não é tarefa fácil para os gestores escolares gerir as escolas de suas residências, ou mesmo para aqueles que estão atuando na escola em função da falta dos recursos tecnológicos em suas casas.

\section{O trabalho do gestor escolar em tempos de pandemia}

A gestão escolar é a arte de fazer com que as atividades inerentes à escola aconteçam a partir da colaboração de um grupo de pessoas embora nem sempre a diretoção tenha controle sobre os servidores que atuam nas escolas (Leal, 2016). A partir deste conceito levantamos a hipótese de que se o trabalho da gestão escolar já apresenta este desafio inicial, que é o de conquistar a participação e envolvimento da equipe nas atividades da escola de forma presencial, desenvolver as ações inerentes ao cargo, decidir sobre o andamento da escola de forma remota e sem o contato direto com as pessoas para fazer acompanhamento e auxiliar no momento de necessidade, pode se constituir um grande desafio para os gestores escolares, neste momento de pandemia.

Além de acompanhar as atividades dos servidores técnicos, os diretores precisam, também, manter o contato constante com professores e familiares para acompanhamento das atividades essenciais à escola. Isso porque este procedimento é relevante para que os processos de ensino e de aprendizagem ocorram de forma eficaz e com o mínimo de transtorno possível, tanto para os professores, quanto para os alunos e seus familiares, durante o período de ensino remoto emergencial.

Gerir a escola "é organizar, mobilizar e articular todas as condições materiais e humanas necessárias para garantir o avanço dos processos socioeducativos das escolas" (Martins; Bocanelli, 2010, p. 81). Nesse caso o dirigente, sendo o principal responsável pela escola, tem atribuições que lhes são demandadas para efetivação das ações que viabilizem o alcance de bons resultados educacionais. Por esse viés percebe-se o desafio enfrentado pelos dirigentes para realizar a mobilização e articulação das pessoas de forma remota. Como afirma Peres (2020) o gestor passou a dar conta de muitas frentes porque existia a constante preocupação com as melhorias dos índices educacionais e com a pandemia passou a preocupar-se também com a transposição das aulas presenciais para aulas remotas, "administrando com isso, o seu próprio despreparo, e também, o despreparo dos docentes para o uso de ferramentas tecnológicas para aulas virtuais, e em muitos casos, curvando-se para a ausência de recursos tecnológicos dos alunos e de suas famílias" (p. 24).

Segundo Vandersen e Freitas (2014) para executar suas atribuições é essencial que o diretor reúna três habilidades específicas: habilidades técnicas: tomada de decisões e resoluções de conflitos; habilidade humana: relacionar e solucionar conflitos; habilidade conceitual: visão sistêmica, isto é, capacidade de compreender a escola como um todo.

Soares, Ferreira e Araújo (2020) afirmam que alguns gestores não entendem que, dentre suas funções, a pedagógica é de fundamental importância e por isso agem apenas como simples administradores. Os referidos autores pontuam a importância de o gestor saber dividir tarefas, saber ouvir, promover participação, respeitar o bem comum e conhecer as reais necessidades da comunidade escolar. Entende-se que essa interação 
ficou bem mais evidente agora com a pandemia da Covid-19, uma vez que as decisões necessitam ser discutidas e socializadas para análise da real possibilidade de serem tomadas.

$\mathrm{Na}$ prática e com a pandemia a função do diretor ficou muito mais complexa, ou seja, demandas que não haviam sido pensadas e, possivelmente, muitas dúvidas para respondê-las. Um fator importante na gestão da escola com a pandemia é a comunicação e informação, imprescindíveis para viabilizar o contato com técnicos, professores, alunos e familiares, para organizar os rearranjos para as atividades pedagógicas de forma remota, bem como o trabalho de quem continua indo à escola para resolver a parte burocrática e tomar decisões. Peres (2020) reforça a importância do gestor escolar no desempenho de suas funções e diante desse novo cenário as conquistas referentes ao processo de gestão escolar se alteeram radicalmente com as novas demandas causadas pela chegada da pandemia no Brasil.

Segundo o Ministério da Saúde (2020) a "Covid-19, é uma doença causada pelo coronavírus, denominado Sars-cov-2, que apresenta um espectro clínico variando de infecções assintomáticas a quadros graves. Essa doença mudou de forma abrupta a forma de gerir o cotidiano escolar por ter que garantir a continuidade do trabalho mesmo de forma remota e emergencial teve que se reinventar para manter a parte pedagógica e administrativa da escola funcionando. Para Ferreira (2020) ninguém estava preparado para essa nova forma de lidar com a educação remota com acompanhamento de casa, nem os professores, nem gestores, nem a família, portanto, "a primeira coisa a se fazer é entender que a adaptação não será perfeita e que todos estão dando o seu melhor nessa nova realidade" (p. 1).

É o momento em que a comunidade escolar deve "dar as mãos simbolicamente, testar coisas novas e repensar se a Educação e a dinâmica escolar que estávamos exercendo é a que faz mais sentido ou não para o momento atual" (Ferreira, 2020, p. 1). A autora reforça que apesar de não existir uma resposta pronta não podemos perder de vista a oportunidade de construir novos caminhos para a escola. Neste ponto cabe ao gestor escolar aproveitar o momento e pensar em conjunto com a equipe gestora, professores e alunos, outras possibilidades para não perder o contato geral com os alunos devido ao isolamento social e como sugestão.

Sobre equipe gestora Bimbarati (2020), ao ouvir relato de experiência de uma escola nesse período de pandemia, deixa evidente a importância do apoio técnico e pedagógico da gestão escolar e das secretarias de educação para minimizar o impacto das mudanças pelas quais todos estão passando. Esse apoio é fundamental como suporte para dúvidas e buscar estratégias para sanar problemas de acesso da comunidade escolar e manter, em parte, as atividades pedagógicas da escola.

Além do distanciamento da comunidade escolar, do ensino remoto os gestores terão que pensar propostas de retorno escolar e considerarem a

readequação do calendário escolar; possibilidade de retorno gradual e de trabalhar com uma porcentagem reduzida de aluno s em sala de aula, quer seja em sistema de rodizio ou não; ausência de profissionais do grupo de risco; necessidade da organização de regras de distanciamento social; 
intensificação das ações dos protocolos de higiene e saúde exigidos pelos órgãos sanitários, visando minimizar possíveis riscos de contaminação e detecção precoce de sintomas da covid 19, dentre outras questões.

\section{Metodologia}

Para o desenvolvimento deste estudo utilizamos como metodologia a pesquisa exploratória e qualitativa (Yin, 2016). Neste caso buscamos compreender como os gestores das escolas municipais de Jacobina/BA passaram a desenvolver suas atividades cotidianas de gestão escolar com a pandemia da Covid-19.

Inicialmente foi feita uma pesquisa bibliográfica e documental para subsidiar teoricamente a pesquisa. Para coleta dos dados optou-se pela aplicação de questionário. A elaboração das proposições do questionário, visando a analisar o trabalho dos diretores acerca das atividades de gestão durante o período da pandemia, constou de questões abertas e fechadas, intercaladas entre si, que permitiram obter dados e recolher informações específicas, possíveis de serem aprofundadas nas análises.

Foi solicitado a uma das gestoras escolares, por WhatsApp, que repassasse o link do questionário para o grupo de gestores e que não foi excluído nenhuma modalidade de ensino, as quais as escolas municipais dispõem, porque o objetivo era compreender como todas as escolas, dos diversos segmentos, estavam atuando durante esse período. $O$ questionário foi enviado para os 35 gestores escolares da rede municipal de ensino de Jacobina/BA e respondido por 16 deles. Os respondentes envolvidos nos deram um bom panorama de como algumas escolas deste município estão atuando e como os gestores estão se mobilizando para desenvolver suas atividades profissionais.

Depois de organizados, os dados foram analisados e interpretados a partir de planilhas Excel com elaboração de gráficos e foram utilizadas nuvens de palavras, criadas no programa WordArt, a fim de responder ao objetivo aqui exposto.

\section{Perfil dos gestores}

Participaram da pesquisa 16 gestores de escolas públicas municipais de Jacobina/BA, sendo registrada uma representatividade eminentemente feminina (14) na gestão escolar deste município.

Quanto à faixa etária todos os participantes têm mais que 30 anos de idade, sendo que três têm mais de 46 anos e 13 estão na faixa etária entre 31 a 45 anos de idade. Com referência ao tempo de atuação na gestão escolar quase $70 \%$ dos gestores tem pouca experiência na área, conforme podemos observar no gráfico 3 . 
Gráfico 1 -

Tempo de atuação dos participantes na gestão escolar.

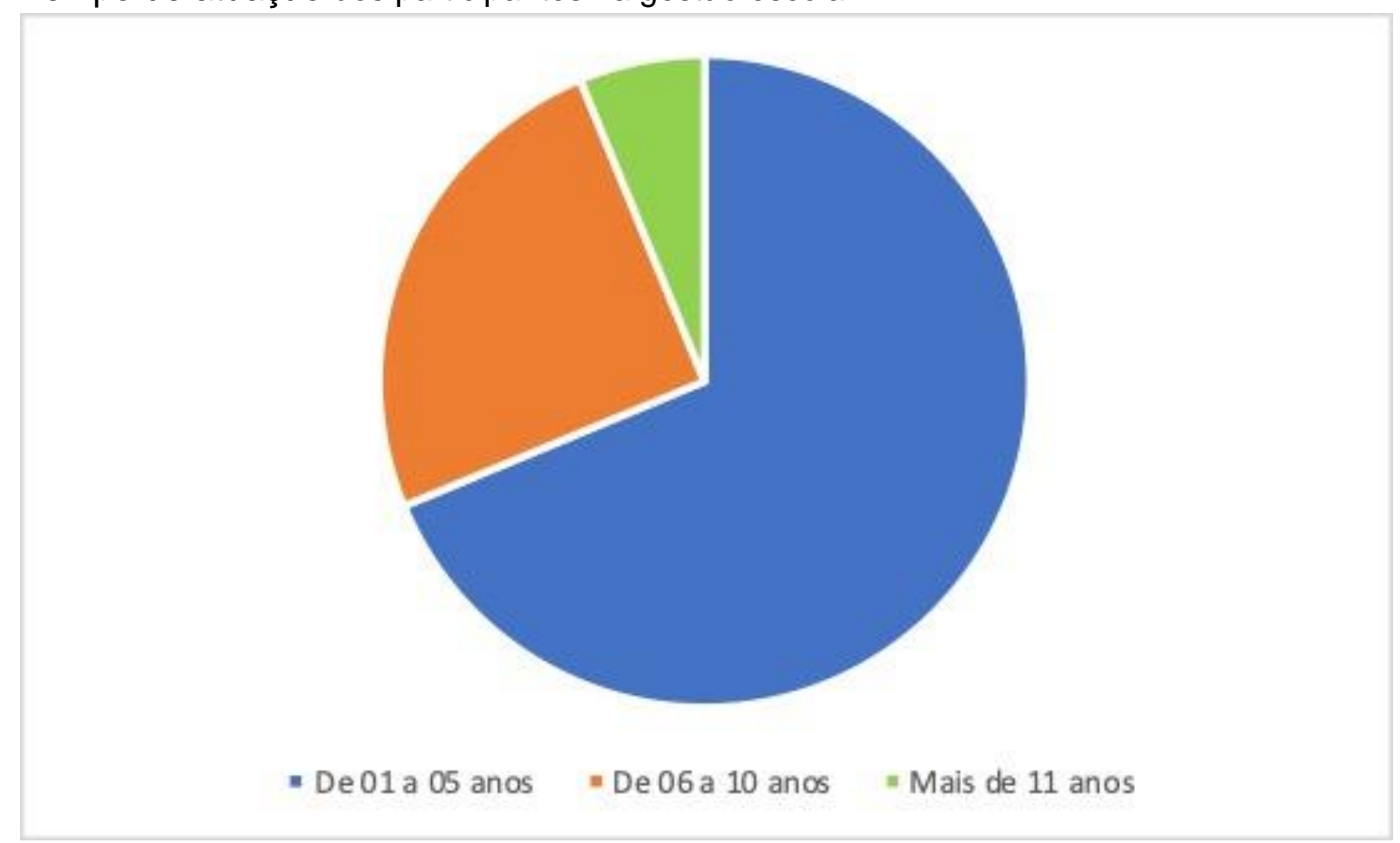

Fonte: autores.

Com referência a formação inicial 12 têm licenciatura em Pedagogia (75\%); três em Letras e um em Geografia. Sobre a continuidade formativa dos participantes dois têm graduação; $80 \%$ dos participantes são especialistas e uma tem pós doutorado.

\section{Sobre as escolas}

Com referência às escolas foi investigado o porte, tipo e quais etapas de ensino são ofertadas: dez são de pequeno porte ${ }^{5}$, três de médio, duas de grande porte e uma especial. Quanto à oferta de ensino dez escolas são de educação infantil; oito de ensino fundamental I, cinco de ensino fundamental II e três de EJA.

\section{Sobre o trabalho dos gestores na pandemia}

Foi perguntado aos gestores onde eles têm realizado suas atividades neste período de isolamento social. De acordo com as respostas ao questionário a maioria dos gestores estão desenvolvendo suas atividades, tanto administrativas, quanto pedagógicas, em casa e na escola. Dois gestores estão trabalhando apenas em casa. Segundo os gestores esta rotina de trabalho foi instaurada logo que foi declarada a necessidade de isolamento social.

\footnotetext{
${ }^{5}$ Para fins de organização/provimento do quadro de pessoal, ou seja, número de profissionais necessários para o funcionamento das escolas, no município de Jacobina/BA as escolas são classificadas a partir das seguintes tipologias (Jacobina, 2013): I - Escola de Pequeno Porte - EPP: aquela que tem registrado o quantitativo de 120 a 300 alunos matriculados; II- Escola de Médio Porte - EMP: aquela de 301 a 700 alunos matriculados; III- Escola de Grande Porte - EGP: de 701 a 1.600 alunos matriculados; IV) Escola de Porte Especial - EPE: aquelas com mais de 1.600 alunos matriculados. As escolas com número inferior a 120 alunos serão nucleadas à escola mais próxima.

\begin{tabular}{l|l|l} 
Regae: Rev. Gest. Aval. Educ. & Santa Maria 10
\end{tabular}

ก. 19

e63188, p. 1-13

2021
} 
Quanto à necessidade de realizar atividades no espaço escolar, a participante Aruana relata que "mesmo no início da pandemia foram solicitadas algumas informações que necessitavam da nossa presença na escola, e muitas vezes por falta de internet temos que realizar as atividades em casa". Ubiratan também registra que depois que tudo se agravou foi obrigado a manter cuidado redobrado e evitar o contato com mais pessoas, principalmente porque, segundo o mesmo, nem todo mundo sabe se comportar para não agravar mais ainda o problema da pandemia da Covid-19. Nina afirmou que "gostaria de trabalhar mais em casa para não me expor. Mas devido a falta de computador e alguns documentos estarem na instituição, tenho que sair mais vezes de casa."

Foi perguntado se tinham computador e acesso a internet banda larga para realização das atividades funcionais em suas residências. Um pouco mais que $80 \%$ dos gestores dispõe destas ferramentas em suas casas, contudo três gestores não têm computador, nem acesso a internet em suas residências.

Foi perguntado aos gestores se suas escolas retornaram às atividades pedagógicas com aulas remotas e $100 \%$ das escolas adotaram o ensino remoto emergencial, desenvolvendo atividades a partir das estratégias descritas no quadro 4.

Tabela 1 -

Estratégias adotadas pelas escolas para o desenvolvimento do ensino remoto.

\begin{tabular}{l|c}
\hline \multicolumn{1}{c|}{ Estratégias } & № de escolas que adotou \\
\hline $\begin{array}{l}\text { Aulas ministradas pelos professores em plataformas on- } \\
\text { line }\end{array}$ & 4 \\
\hline $\begin{array}{l}\text { Aulas gravadas pelos professores em plataformas on- } \\
\text { line }\end{array}$ & 4 \\
\hline Envio de atividades impressas para os alunos & 5 \\
\hline $\begin{array}{l}\text { Envio, pelas professoras, de roteiros de atividades } \\
\text { diárias, vídeo-aulas, áudios e orientações via grupo de } \\
\text { WhatsApp para os alunos }\end{array}$ & 7 \\
\hline
\end{tabular}

Fonte: autoras.

Com referência à comunicação com as famílias foi perguntado aos gestores de que forma eles têm conseguido fazer contato com as famílias para buscar informações sobre os alunos. A figura 1 representa os meios utilizados pelos gestores para este fim. 
Figura 1 -

Forma de comunicação dos gestores com as famílias.

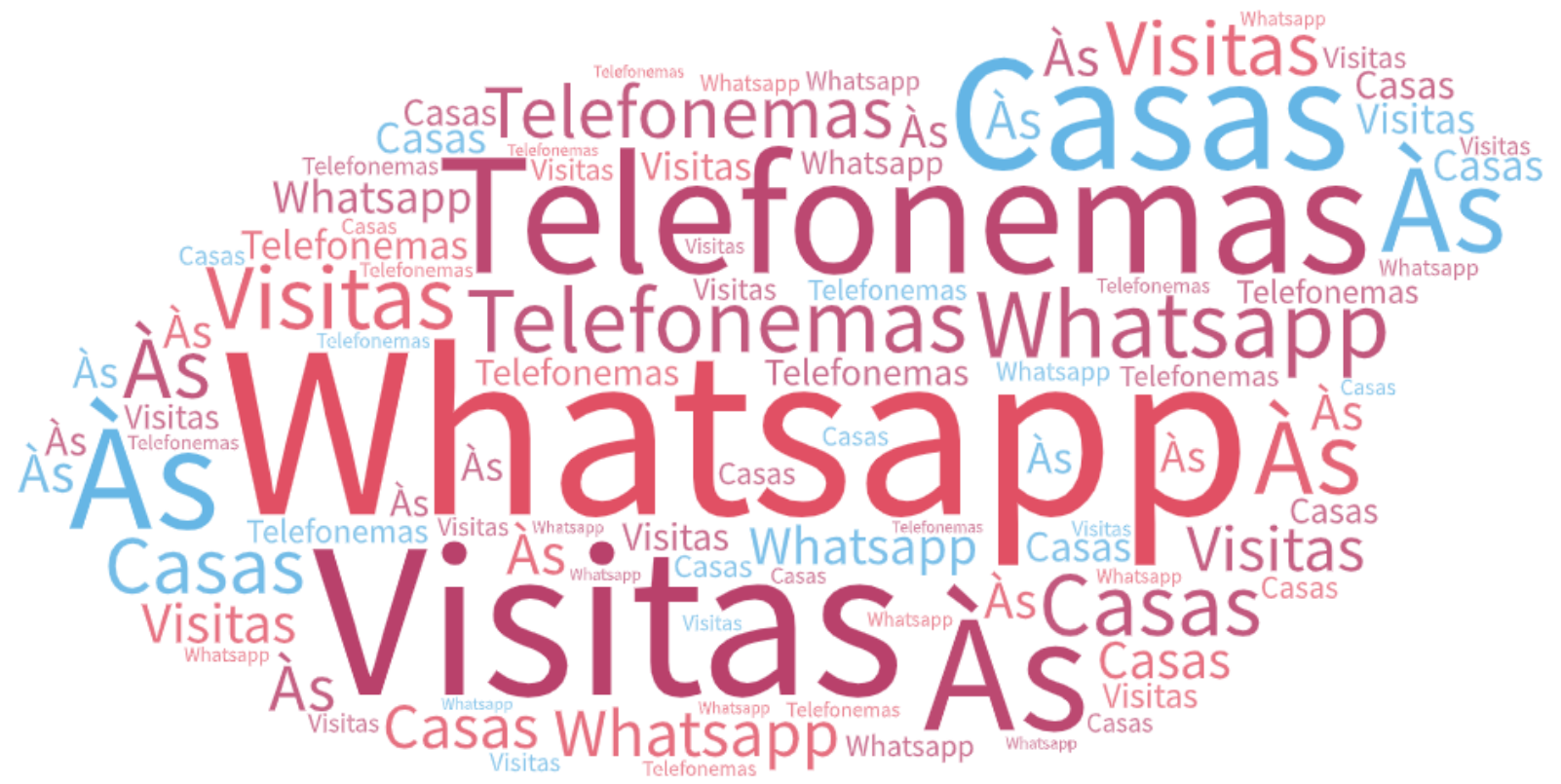

Fonte: autores.

A análise da figura permite-nos afirmar que os meios mais eficazes para comunicação com as famílias tem sido o WhatsApp, visita às casas dos alunos e telefonemas. Por estes recursos foi possível viabilizar, junto aos familiares, o início das atividades remotas com os alunos. Vale ressaltar que as visitas podem se configurar em exposição desses profissionais ao coronavírus, uma vez que não é possível ter conhecimento se as famílias estão se cuidando para evitar o contágio.

Com referência ao contato com a equipe docente e técnica da escola e com a Semec, $100 \%$ dos gestores tem utilizado grupos de WhatsApp para comunicação e $70 \%$ dos participantes estão realizando reuniões em plataformas. Os gestores sinalizam, ainda, que eventualmente realizam comunicação por telefone ou e-mail.

Sobre a adesão dos professores ao ensino remoto em $75 \%$ das escolas houve adesão de todos os professores para esta alternativa emergencial de garantir a continuidade dos estudos aos estudantes. Contudo, $25 \%$ dos gestores registram que mais da metade dos professores aderiram, porém, manifestaram muita resistência.

Já com referência à adesão dos alunos a esta prática os gestores registraram que não houve uma adesão total: $94 \%$ registrou que houve adesão de mais da metade dos alunos e $6 \%$ que a metade dos estudantes de suas escolas aderiram ao ensino remoto. Estes dados podem apresentar um indicativo de evasão escolar neste período de pandemia.

Os gestores acreditam que a não adesão pode ser justificada, sobretudo, pela insuficiência dos recursos - não possuir aparelho de celular, não haver internet banda larga, utilizar pacotes de dados e estes não comportarem o uso durante as atividades, morar em localidades onde não tenha rede operadora de celular -, por parte dos alunos e seus familiares, para acompanhamento das atividades remotas. Acrescenta-se a este 
fator a possibilidade de uso compartilhado dos recursos tecnológicos com os pais, o que impede, ocasionalmente, o acompanhamento. Além disso, por não ser uma situação de curto período de tempo, os alunos, majoritariamente acima de 14 anos, passaram a desenvolver alguma atividades remuneradas neste período, para complementação da renda familiar, inviabilizando a participação em atividades escolares.

No que concerne à entrega de materiais impressos sinalizaram que a distribuição é feita de maneira insuficiente pela Semec, uma vez que realiza-se apenas nas localidades rurais em que há a comprovação da impossibilidade do acompanhamento online e, ainda assim, não há regularidade dessa entrega.

Também foi perguntado aos gestores como está sendo a participação da Semec no auxílio às escolas para o ensino remoto. Conforme a análise dos dados apresentados nos questionários $50 \%$ dos gestores sinalizam que a participação da Semec tem sido muito pouca e dois relatam que a secretaria ainda não teve participação nesse processo. Ainda foram coletados os relatos descritos na seqüência: "Na teoria, tem buscado assessorar, na prática, pouca coisa tem sido feita" (Yara); "Bem positivo, com formação via aplicativo com a coordenadora da educação infantil" (Janaina); "Ajudam sempre que solicitamos e se preocupam em nos procurar" (Nina); "Tem nos orientado em alguns aspectos" (Aruana); "Precisa melhorar" (Iracema); "Mais ou menos, pois estão exigindo muito do professor" (Ubiratan); "Até o momento apenas sugestivo, mas nada foi aplicado ainda" (Piatã); "Tem dado o suporte necessário quando solicitada" (Potira); "Está dando todo suporte com formação on-line para nós gestores através da coordenadora da educação infantil e assim fazemos os mesmos com nossos professores" (Jurema); "Estão monitorando e agora iremos preencher umas fichas" (Poti).

É possível inferir que as maiores dificuldades encontradas pelos gestores para o desenvolvimento das atividades inerentes à gestão escolar recaem sobre o uso dos recursos tecnológicos e o risco de infecção. Sobre isto podemos entender que existe uma necessidade de investimento em formação continuada para os gestores escolares, voltada para o uso de recursos tecnológicos nas rotinas da gestão.

Os gestores sinalizam também sobre a dificuldade dos professores em lidarem com os recursos tecnológicos e, por muitas vezes, a resistência de alguns docentes em fazer adesão ao uso das tecnologias. Essa situação nos leva a entender que, embora possuam formação acadêmica, boa parte dos docentes não investe em formação continuada, sobretudo na área tecnológica, portanto, para além da não adesão, o que se percebe é mesmo a falta de habilidade para lidar com as tecnologias. Assim, neste novo cenário instaurado para a educação, novas atribuições somaram-se à tantas já relacionadas ao trabalho do gestor:

O gestor, além da constante preocupação com as melhorias dos índices educacionais, passou a preocupar-se com a transposição das aulas presenciais para aulas em ambientes virtuais, administrando com isso, o seu próprio despreparo, e também, o despreparo dos docentes para o uso de ferramentas tecnológicas para aulas virtuais, e em muitos casos, curvando-se para a ausência de recursos tecnológicos dos alunos e de suas famílias. Considerando a atual realidade, o gestor precisará inovarse, especialmente, diante de fenômenos tão complexos e concretos. 
Nunca, em nenhum momento, em especial no Brasil, os cursos de formação docente, de atualização, de pós-graduação se imaginaram desenvolvendo habilidades e conhecimentos para a atuação profissional em época de pandemia. (Peres, 2020, p. ???)

Outras dificuldades elecandas foram:

"A comunicação, pois as vezes a Semec solicita coisas com muita urgência e temos muito pouco tempo para enviar, e quando recebem não nos dão uma devolutiva." (Yara)

"Saber lidar com alguns professores." (Nina). A resistência em adaptar-se às novas demandas de trabalho advindas da pandemia e em cumprir as determinações da Semec, sobretudo pela incerteza, ainda, da validação desse trabalho para o ano letivo de 2020, somado ao excesso de cobranças e pouco suporte, especialmente para docentes do Ensino Fundamental II e da EJA.

"Muitas são as dificuldades para gerir uma unidade educacional neste momento: alinhar funcionários no rodízio, na escola, de forma segura; garantir a execução de um trabalho com qualidade pedagógica para os alunos; conseguir o retorno desses alunos como parte importante do processo de aprendizagem; manter a parceria dos responsáveis na execução das atividades; entre outras." (Aruana)

"Reuniões remotas com funcionários." (Iracema)

"As plataformas virtuais para reunião, o acesso às mães e às crianças também está sendo complicado para o retorno das atividades remotas." (Jurema)

"Restrição de pessoas no atendimento, pois alguns funcionários são do grupo de risco." (Piatã)

Foi perguntado aos gestores sobre que alterações a pandemia trouxe para a rotina da gestão escolar: $90 \%$ dos gestores registraram que a carga horária de trabalho dos gestores escolares foi alterada significativamente, pois estão trabalhando muito mais que nos períodos de normalidade. Essa situação vem sendo reclamação de diversos profissionais da educação porque ao desenvolver trabalhos de forma remota é como se eles estivessem à disposição da Secretaria, independente de sua carga horária semanal. Existe um excesso de solicitações e todas com retorno emergencial, o que pode causar transtornos no acompanhamento das demais ações da escola.

Outras alterações que foram registradas por mais da metade dos gestores foi a falta de contato físico com os colegas e a solidão na escola, uma vez que a grande maioria está indo para a escola em momentos pontuais, em turnos de trabalhos, nos quais as escalas limitam o número de funcionários e reduzem o tempo de permanência na escola.

"Ficou provado que trabalho em grupo sempre será a melhor opção." (Yara)

"Temos que nos reinventar e nos tornar mais tecnológicos." (Poti) 
"Muita dificuldade de manter a relação família/escola." (Nina)

"O trabalho aumentou, ficou mais difícil de acompanhar, a quantidade de atividades e reuniões on-line têm sido desgastantes." (Piatã)

"Nem sei explicar, tem sido bem difícil por conta da falta do contato, gosto de resolver as coisas pessoalmente, de estar todos os dias na escola, o silêncio na escola tem sido assustador, chegar na escola e não ter ninguém para abraçar, conversar, comer junto, etc." (Ubiratan)

"Alterou bastante pois, agora não temos dia e nem horas para trabalhar, a todo momento temos que responder pais, professoras e a Semec." (Aruana).

"Alterou tanto a forma de trabalho, usando mais a tecnologia ao nosso favor, quanto a forma de olhar para o próximo com cuidado." (Janaina)

\section{Considerações finais}

A pandemia da Covid-19 alterou a forma das pessoas atuarem em relação ao trabalho que passou a ser realizado de forma remota em diversos estabelecimentos, bem como de se relacionar, por ser necessário manter um distanciamento seguro para evitar o contágio ou transmissão do vírus. As escolas precisaram ser fechadas para manter um isolamento social como meio de evitar a transmissão do vírus.

Levando em consideração essas circunstâncias e as novas formas para manter a parte pedagógica em funcionamento, os dirigentes das escolas municipais de Jacobina/BA tiveram que buscar novas maneiras de gerir as escolas de forma remota e manter o contato efetivo com os alunos, professores e demais servidores da escola.

Vale ressaltar que os gestores estão envidando esforços e desenvolvendo ações para garantir a continuidade e qualidade do processo de ensino e aprendizagem. Estes profissionais estão enfrentado dificuldades, em função do número de atividades que precisam executar para manter parte das atividades da escola em funcionamento, mesmo com o distanciamento social.

\section{Referências}

BRASIL. O que é a covid-19. Brasília: Ministério da Saúde, 2020. Disponível em https://coronavirus.saude.gov.br/sobre-a-doenca. Acesso em 15 out. 2020.

BIMBARATI, Ana Paula. Como estão as escolas de referência no Ideb na quarentena? Revista Nova Escola. Acesso em: https://novaescola.org.br/conteudo/19592/como-estaoas-escolas-de-referencia-no-ideb-na-quarentena. Acesso em 15 out. 2020.

FERREIRA, Anna Rachel. Mudança de rotina: como se manter próximo das famílias em tempos de pandemia. Revista Nova Escola São Paulo. Acesso em: https://novaescola.org.br/conteudo/19087/mudanca-de-rotina-como-se-manter-proximodas-familias-em-tempos-de-pandemia. Acesso em 15 out. 2020.

JACOBINA/BA. Lei municipal n. 1.231, de 17 de dezembro de 2013: dispõe sobre o plano de cargos, carreira e remuneração dos profissionais da educação básica do município. 17 de dezembro de 2013. 
LEAL, lone O. Jatobá. A percepção dos diretores acerca da gestão das escolas municipais de Jacobina/BA. Salvador: Uneb, 2016. 164f. Tese (Doutorado em Educação). Programa de Pós-graduação em Educação e Contemporaneidade. Universidade do Estado da Bahia.

PERES, Maria Regina. Novos desafios da gestão escolar e de sala de aula em tempos de pandemia. Revista Administração Educacional, Recife, v. 11, n . 1, 2020, p. 20-31.

ROHSNER, Juliana. Gestão escolar e pandemia: novos e antigos desafios e possibilidades. E-Docente, São Paulo. Disponível em https://www.edocente.com.br/gestao-escolar-e-pandemia-novos-e-antigos-desafios-epossibilidades. Acesso em 15 out. 2020.

SOARES, Erineuda do Amaral; FERREIRA, Helena; ARAÚJO, Patrícia. O papel do gestor escolar e sua implicação no processo de ensino aprendizagem. ENCONTRO ESTADUAL DA ANPAE, 4, 2020. Brasília: Anpae, 2020, p. 162-167.

MARTINS, Ana P. Maioli; BOCANELLI, Cláudio R. O papel do diretor de escola frente aos novos desafios da gestão escolar. Colloquium Humanarum, Presidente Prudente, v. 7, n. 2, 2010, p. 80-85.

YIN, Robert K. Pesquisa qualitativa do início ao fim. Porto Alegre. Penso, 2016.

VANDRESEN, Ana Sueli Ribeiro; FREITAS, Maria do Carmo Duarte. Conhecimentos administrativos necessários para 0 gestor. Disponível em http://www.diaadiaeducacao.pr.gov.br/portals/pde/arquivos/352-4.pdf. Acesso em 3 fev. 2015.

Ione Oliveira Jatobá Leal é professora na Universidade do Estado da Bahia.

Orcid: https://orcid.org/0000-0003-3653-0268.

Endereço: Rua Otávio Mangabeira, 97 - 44700-000 - Jacobina - BA - Brasil.

E-mail: ionejatoba@gmail.com.

Cristiane Regina Dourado Vasconcelos é professora na Escola Municipal Cidade Vitória da Conquista.

Orcid: https://orcid.org/0000-0003-4258-7375.

Endereço: Rua Edna dos Santos, 207 - 42709-460 - Lauro de Freitas - BA - Brasil.

E-mail: dourado.cris@gmail.com.

Lenizan Passos Rios é gestora na Escola Núbia Maria Mangabeira.

Orcid: https://orcid.org/0000-0003-0278-9773.

Endereço: Rodovia Jacobina a Miguel Calmon, 62 - 44700-000 - Jacobina-- BA Brasil.

E-mail: lenipassos85@gmail.com. 
Jomária Alessandra Queiroz de Cerqueira Araújo é gestora na Escola Municipal 22 de Abril.

Orcid: http://orcid.org/0000-0002-8046-3018.

Endereço: Rua dos Bandeirantes, 841 - 40260-001 - Salvador - BA - Brasil.

E-mail: akeiroz@gmail.com.

Critérios de autoria: coletivamente os autores conceberam a ideia, criação, execução, discutiram os resultados, fizeram análise, interpretação, redação e revisão da versão final. A aplicação do questionário que ficou sob a responsabilidade de Lenizan Rios.

Recebido em 23 de novembro de 2020.

Aceito em 17 de março de 2021.

(c) $($ i) $(9)$ 